\title{
Quinoxalines Derived from Disaccharides with $o$-Phenylenediamine under Weakly Acidic Reflux Conditions
}

\author{
Naofumi Morita, Keiichi Inoue and Masanosuke TAKagi \\ Laboratory of Food Chemistry, Department of Agricultural Chemistry, \\ College of Agriculture, University of Osaka Prefecture, \\ Sakai, Osaka 591, Japan \\ Received June 10, 1985
}

\begin{abstract}
Quinoxaline derivatives from disaccharides (isomaltose, maltose, laminaribiose, trehalose and sucrose) and $o$-phenylenediamine (OPD) under weakly acidic reflux conditions were subjected to GLC and GC-MS analyses.

Three high-molecular-weight quinoxaline derivatives (IA-I, -II and -III) were obtained from isomaltose in a yield of $90 \%$, indicating no splitting of the glucosidic linkages. Both low- and highmolecular-weight quinoxaline derivatives were obtained from $5 \mathrm{~mm}$ maltose. From $50 \mathrm{~mm}$ maltose, a low-molecular-weight quinoxaline, GA-I, was obtained predominantly. Quinoxalines from laminaribiose were both high (LA-I and -II) and low (ATBQ, GA-I, G-1 and GA-II) molecularweight derivatives, in yields of $18 \%$ and $48 \%$, respectively. LA-I and -II were stereoisomers, at the C-3 position, of laminaribiose. Trehalose gave no quinoxalines, and sucrose gave only small amounts of low-molecular-weight quinoxalines.

From these results, we found that 1,6-linkages of the disaccharides used are most resistant to the OPD degradation, followed by the 1,4- and 1,3-linkages, in that order. Possible pathways for the formation of quinoxalines are proposed.
\end{abstract}

We have been investigating the degradation of carbohydrates in alkaline ${ }^{1 \sim 4)}$ and acidic media $^{5 \sim 9)}$ using $o$-phenylenediamine (OPD). This OPD method is very convenient for the qualitative and quantitative elucidation of degradation products of sugars. In alkaline media, various kinds of dicarbonly compounds were formed through the splitting of the carbon-carbon linkages, followed by condensation with OPD, resulting in the quantitative formation of quinoxaline derivatives. These quinoxalines are specific to the original structure or the linkages of the sugar. In weakly acidic media, several kinds of quinoxaline derivatives were also formed, but no carboncarbon linkages were split, and only isomerization or deoxygenation of hydroxyl groups occurred. In weakly acidic media, five kinds of quinoxaline derivatives were formed from hexoses ${ }^{5,7)}$; four quinoxalines and one benzimidazole from methylpentoses ${ }^{8)}$; and three quinoxalines from pentoses. ${ }^{6,9)}$ Hence, we have been interested in clarifying the reaction of OPD with disaccharides in weakly acidic media for studies on the mode of epimerization or enolization of carbohydrates, ${ }^{10,11}$ ) since the reactions are partly restricted by the linkages, leading to the formation of specific heterocyclic compounds.

In this paper, we describe the characterization of products obtained from maltose, isomaltose and laminaribiose with OPD under weakly acidic, deoxygenated and heated conditions, and discuss possible pathways for the formation of quinoxalines.

\section{RESULTS AND DISCUSSION}

\section{1) Separation of quinoxaline derivatives from isomaltose}

A mixture containing $5 \mathrm{~mm}$ isomaltose and $50 \mathrm{~mm}$ OPD was heated at $80^{\circ} \mathrm{C}$ for $3 \mathrm{hr}$ in a solvent system of $\mathrm{MeOH}-\mathrm{AcOH}-\mathrm{H}_{2} \mathrm{O}(8: 1: 2$, $\mathrm{v} / \mathrm{v}$ ), and then a sample of the solution was 


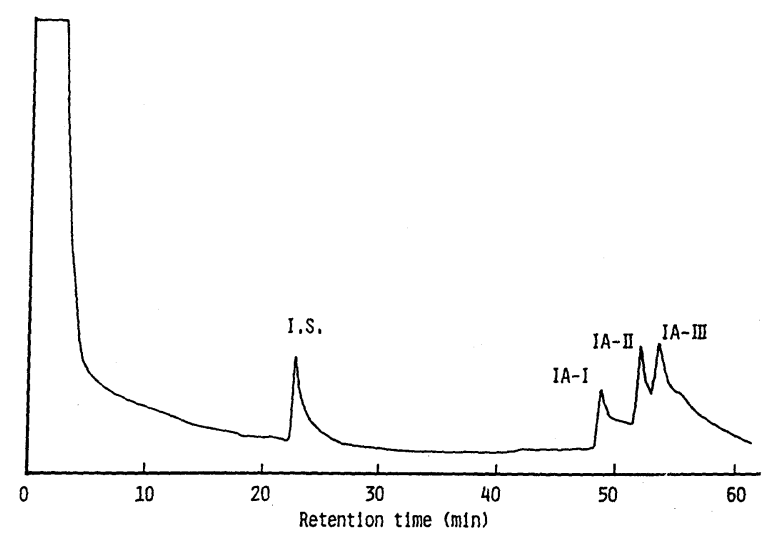

FIG. 1. GLC of TMS-Derivatives of Quinoxalines from Isomaltose and OPD.

A mixture of isomaltose $(5 \mathrm{mM})$ and OPD $(50 \mathrm{~mm})$ was refluxed at $80^{\circ} \mathrm{C}$ for $3 \mathrm{hr}$ under deoxygenated conditions. After cooling of the reaction mixture, a sample $(1 \mathrm{ml})$ of the solution was evaporated to dryness and subjected to trimethylsilylation as described in the text. Two $\mu \mathrm{l}$ of the sample was injected into a glass column $(0.2 \times 200 \mathrm{~cm})$ packed with $2 \% \mathrm{OV}-210$, programmed from $140^{\circ} \mathrm{C}$ to $250^{\circ} \mathrm{C}$ at a rate of $2^{\circ} \mathrm{C} / \mathrm{min}$. I.S., internal standard ( $\beta$-phenyl-D-glucoside).

evaporated to dryness and analyzed by GLC after trimethylsilylation, as shown in Fig. 1. All of the quinoxaline derivatives formed probably have one glucose residue in their side chains, judging from their relatively delayed retention times. We could not obtain any low-molecular-weight derivatives, suggesting that the glucosidic linkage of isomaltose did not decompose under these conditions.

For the preparation of these highmolecular-weight quinoxaline derivatives, we worked on a larger scale, with $500 \mathrm{~mm}$ each of isomaltose and OPD with heating for $3 \mathrm{hr}$. After cooling the reaction mixtures, a sample of each solution was evaporated to dryness. The syrup was extracted with $n$-hexane to remove excess OPD, and the solvent layer was discarded. The residue was dissolved in a minimal volume of deionized water, applied on a column of Sephadex G-15 $(2 \times 120 \mathrm{~cm})$, and eluted with deionized water. The UV absorbance of each fraction eluted was measured at $320 \mathrm{~nm}$, and the quinoxaline fractions, IA-I, -II and -III, were pooled and lyophilized.

2) Structural determination of quinoxaline derivatives from isomaltose and $O P D$

Figure 2 shows the results of GC-MS anal-

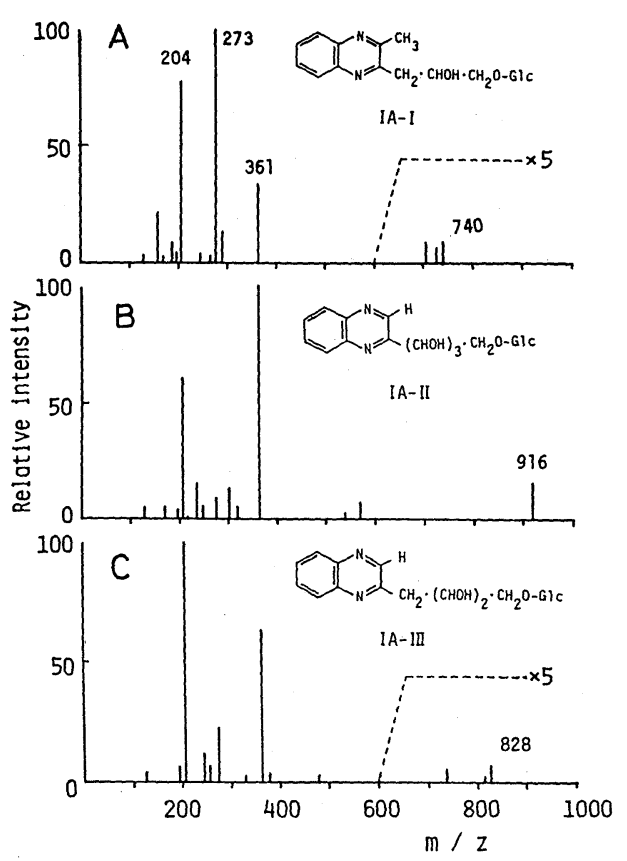

FIG. 2. Mass Spectra of TMS-Derivatives of IA-I (A), II (B) and -III (C).

High-molecular-weight quinoxaline derivatives, IA-I, -II and -III, which are the same materials as shown in Fig. 1, were analyzed by GC-MS. The GC-MS conditions are given in the text.

ysis of IA-I, -II and -III as their TMS-ethers. Quinoxaline IA-I has a molecular ion peak at $m / z 740$, and other characteristic fragment ions 
at $m / z$ 204, 273 (base peak), 289 and 725. The structures of these fragments are:

204, CHOTMS = CHOTMS;

273 ,<smiles>[CH2+]C([OH2+])Cc1nc2ccccc2nc1C</smiles>

289 ,<smiles>Cc1nc2ccccc2nc1CC([O+])[Sn]C[OH2+]</smiles>

$725,\left(\mathrm{M}^{+}-\mathrm{CH}_{3}\right)$;

740 ,

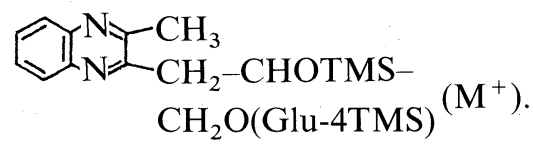

A mixture of quinoxaline derivatives IA-I, -II and -III was hydrolyzed with glucoamylase followed by analysis by GLC as the respective TMS-ethers; GA-I, G-1 and ATBQ were observed. Their chemical structures have been reported $^{5,7)}$ and are also presented under Materials AND Methods in this paper.

From these results together with those of the enzymatic degradation, we concluded that IAI was (2'S)-2-methyl-3-(2'-hydroxy-3'-glucopyranosyloxypropyl)quinoxaline.

IA-II has a molecular ion peak at $m / z$ 916, and other characteristic fragment ions at $\mathrm{m} / \mathrm{z}$ 204, 217, 304, 361 (base peak), 465 and 901. The structures of these fragments are: 204, CHOTMS $=$ CHOTMS $; \quad 217, \mathrm{C}^{+}$HOTMS $\mathrm{COTMS}=\mathrm{CH}_{2}$;

305, $\mathrm{C}^{+}$HOTMS-COTMS $=$CHOTMS;

361 ,<smiles></smiles>

465

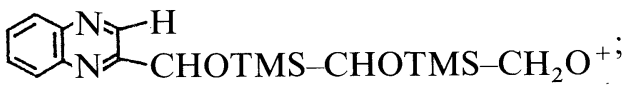

901, $\left(\mathrm{M}^{+}-\mathrm{CH}_{3}\right)$;

916 ,

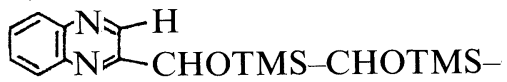

CHOTMS- $\mathrm{CH}_{2} \mathrm{O}($ Glc-4TMS $)$

Enzymatic hydrolysis of IA-II with glucoamylase and subsequent GLC analysis of the liberated quinoxaline as its TMS-ether showed that ATBQ was the constituent quinoxaline moiety of IA-II.

From these results, we concluded that IA-II was $\quad\left(1^{\prime} R, 2^{\prime} S, 3^{\prime} R\right)-2-\left(1^{\prime}, 2^{\prime}, 3^{\prime}\right.$-trihydroxy-4'glucopyranosyloxybutyl)quinoxaline, assum- ing that no special isomerization of maltose residues occurs during refluxing at $80^{\circ} \mathrm{C}$ in a slightly acidic solution.

IA-III has a molecular ion peak at $m / z 828$, and other characteristic fragment ions at $\mathrm{m} / \mathrm{z}$ 204 (base peak), 245, 273, 361, 377 and 813 . The structures of these fragments are: 204, $\mathrm{CHOTMS}=\mathrm{CHOTMS}$;

245 ,

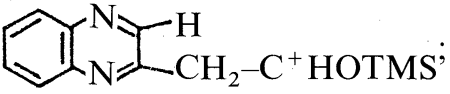

273 ,

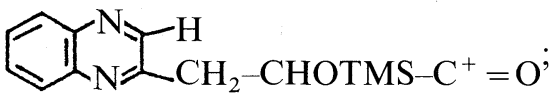

361 ,

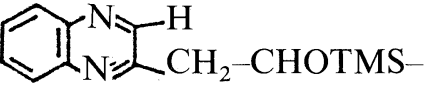
CHOTMS $-\mathrm{CH}_{2}{ }^{+}$;

377 ,
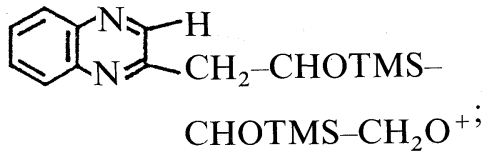

828

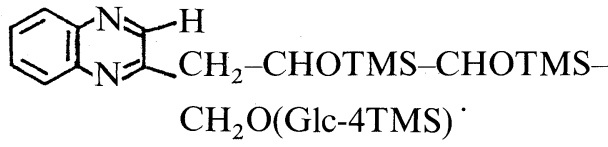

Enzymatic hydrolysis of IA-III with glucoamylase and subsequent GLC analysis of the quinoxaline liberated demonstrated that IA-III includes G-1 as a component.

Consequently the results for IA-III were found to agree with those for $\left(2^{\prime} S, 3^{\prime} R\right)$-2$\left(2^{\prime}, 3^{\prime}\right.$-dihydroxy-4' - glucopyranosyloxybutyl)-quinoxaline, which was obtained from 1,6-linked glucans such as amylopectin or scleroglucan under alkaline and deoxygenated conditions, as reported previously. ${ }^{2,12}$

For quantitative determination of each quinoxaline derivative formed from isomaltose, a sample of the reaction mixture after 3$\mathrm{hr}$ heating of $5 \mathrm{~mm}$ isomaltose and $50 \mathrm{~mm}$ OPD was analyzed by HPLC, as shown in Fig. 3. The proportions of each quinoxaline derivatives were estimated to be: IA-I, $32.5 \%$; IAII, $43.2 \%$; and IA-III, $18 \%$, assuming that these quinoxaline derivatives have similar molecular extinction coefficients, as previously reported. ${ }^{3,5)}$ The total yield as sugar was about $90 \%$. 


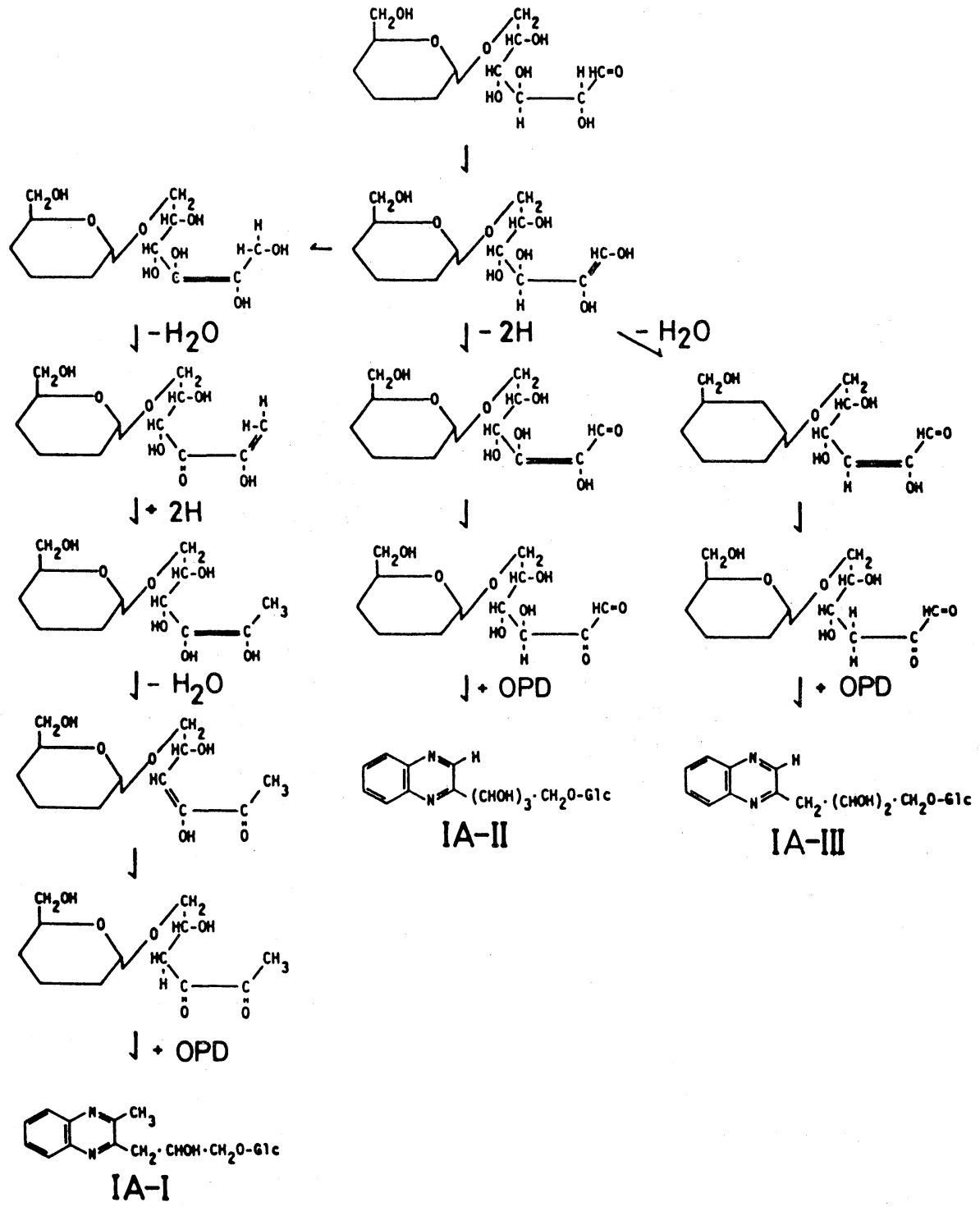

SCHEME I. Proposed Pathways for the Formation of IA-I, -II and -III from Isomaltose and OPD in a Weakly Acidic Solution.

On comparison of the structures and properties of the quinoxaline derivatives formed, we found that they are formed from the reducing end residue of isomaltose, without splitting of its glucosidic linkage.

On the basis of the results of structural determinations of IA-I, -II and -III, Scheme I shows the most probable reaction pathway for the formation of quinoxaline derivatives from isomaltose.
3) Quinoxalines derived from maltose

Figure 4 shows the GLC separation of quinoxaline derivatives, as their TMS-ethers, obtained from $5 \mathrm{~mm}$ maltose and $50 \mathrm{~mm}$ OPD under the same conditions as used for isomaltose. Judging from the delayed retention times on the chromatogram, the quinoxaline in the three peaks, MA-I, -II and -III, probably have one glucose residue in their side chains. The other three quinoxalines of low molecular 


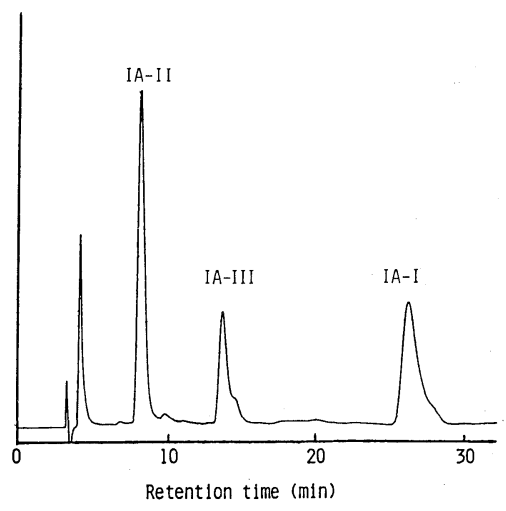

FIG. 3. HPLC of Quinoxalines Derived from Isomaltose and OPD.

An aliquot of the reaction mixture described in Fig. 1 was analyzed by $\mathrm{HPLC}$ using $\mathrm{MeOH}-\mathrm{CH}_{3} \mathrm{CN}-\mathrm{H}_{2} \mathrm{O}(8: 1: 31$, $\mathrm{v} / \mathrm{v}$ ) as an eluent (flow rate, $0.6 \mathrm{ml} / \mathrm{min}$ ), with monitoring at $320 \mathrm{~nm}$. Other experimental details are given in the text.

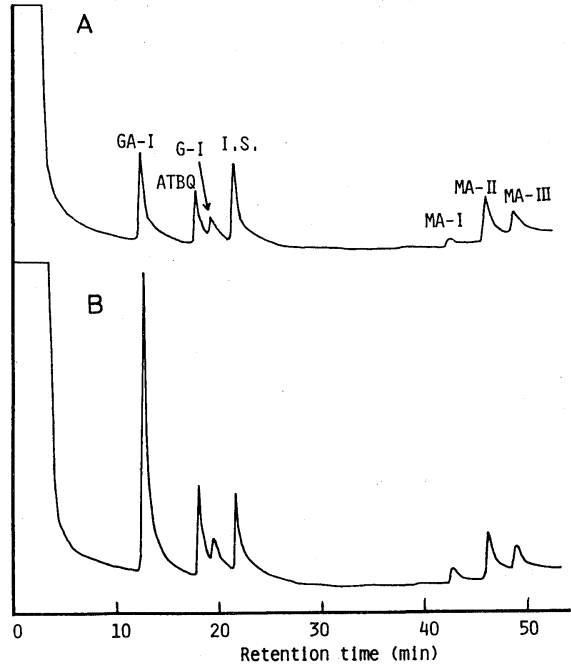

FIG. 4. GLC of TMS-Derivatives of Quinoxalines from $5 \mathrm{~mm}$ (A) or $50 \mathrm{~mm}$ (B) Maltose and OPD.

The experimental details are the same as for Fig. 1.

weight are considered to be GA-I, G-1 and ATBQ on comparison with the retention times of authentic specimens, which were reported previously. ${ }^{5)}$

For the preparation of high-molecularweight quinoxaline derivatives, $50 \mathrm{mmol}$ of maltose was used for the reaction as mentioned above. A sample of the reaction mixture was put on a Sephadex G-15 column. After the removal of low-molecular-weight quinoxaline derivatives, a mixture of MA-I, -II and -III was obtained.

4) Structural determination of $M A-I,-I I$ and $-I I I$ derived from maltose and $O P D$

GC-MS analysis of MA-I, -II and -III derived from maltose was performed for their structural determination, as their TMS-ethers.

MA-I has a molecular ion peak at $m / z 828$, and other characteristic fragment ions at $\mathrm{m} / \mathrm{z}$ 204, 259 (base peak), 271, 361 and 813. The structures of these fragments ions are:

204, CHOTMS $=$ CHOTMS;

259 ,

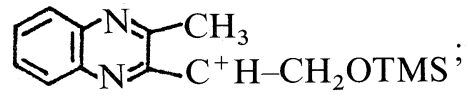

271 ,

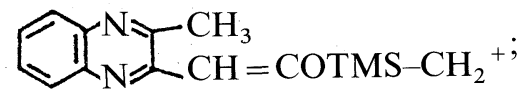

361 ,

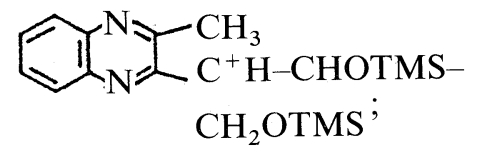

813, $\left(\mathrm{M}^{+}-\mathrm{CH}_{3}\right)$;

828 ,

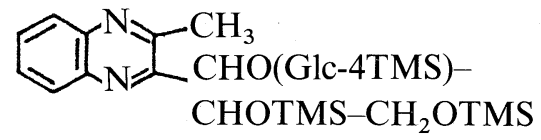

The structure of the quinoxaline moiety of MA-I was further confirmed as follows. MA-I obtained on Sephadex G-15 gel filtration was treated with glucoamylase, and the quinoxaline liberated was analyzed by GC-MS as its TMS-ether. The structures of the main fragment ions are considered to be: 73, TMS (base peak); 147, $\mathrm{CH}_{2} \mathrm{OTMS}-\mathrm{CH}_{2}-\mathrm{CH}_{2} \mathrm{O}^{+}$;

181 ,

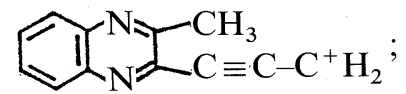

360, $\left(\mathrm{M}^{+}-\mathrm{TMSOH}\right)$;

450 ,

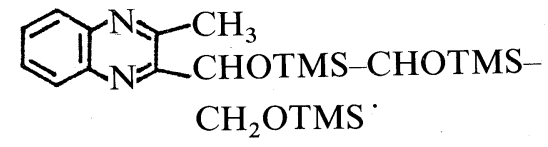

From the results of these GC-MS analyses and the mode of linkage of maltose, together with the results of enzymatic analysis, we may conclude that MA-I is a new compound, $\left(1^{\prime} S, 2^{\prime} R\right)$-2-methyl-3-(1'-glucopyranosyloxy- 
2',3'-dihydroxypropyl)quinoxaline.

GC-MS of MA-II as its TMS-ether showed a molecular ion peak at $m / z 916$, and other characteristic fragment ions at $\mathrm{m} / \mathrm{z} 204$ $($ CHOTMS $=$ CHOTMS $), 217\left(\mathrm{C}^{+}\right.$HOTMS $\mathrm{CH}=$ CHOTMS),

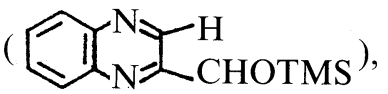

361<smiles></smiles>

$\mathrm{CH}_{2} \mathrm{OTMS}$ base peak), and

$901\left(\mathrm{M}^{+}-\mathrm{CH}_{3}\right)$.

GLC analysis of the enzyme-digested MA-II as its TMS-ether showed that ATBQ was a constituent quinoxaline moiety of MA-II.

From these results and the original structure of maltose, the structure of MA-II was assumed to be ( $\left.1^{\prime} S, 2^{\prime} S, 3^{\prime} R\right)$-2-(glucopyranosyloxy-1', $3^{\prime}, 4^{\prime}$-trihydroxybutyl)quinoxaline.

The GC-MS data for MA-III as its TMSether showed a molecular ion peak at $m / z 828$, and other characteristic fragment ion peaks at $m / z 217,272,361,725$ and 813 . These structures were considered to be: 204 (CHOTMS $=$ CHOTMS, base peak), 217 (C ${ }^{+}$HOTMS$\mathrm{CH}=\mathrm{CHOTMS})$,

272<smiles>[CH2+][Mg]OCCCCc1cnc2ccccc2n1</smiles>

361<smiles>CS(=O)(=O)OCCCCCc1cnc2ccccc2n1</smiles>
$\mathrm{CH}_{2} \mathrm{OTMS}$

725

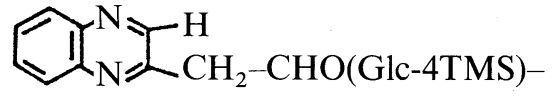
$\mathrm{C}^{+}$HOTMS

$813\left(\mathrm{M}^{+}-\mathrm{CH}_{3}\right)$, and

828

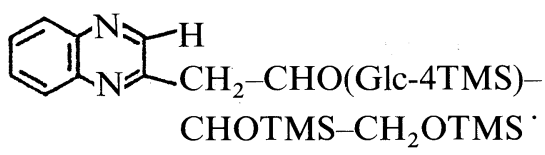

After enzymatic digestion of MA-III which was obtained on gel filtration, the quinoxaline liberated was analyzed by GC-MS as its TMSether. G-1 was found to be a constituent quinoxaline moiety of MA-III. Consequently,

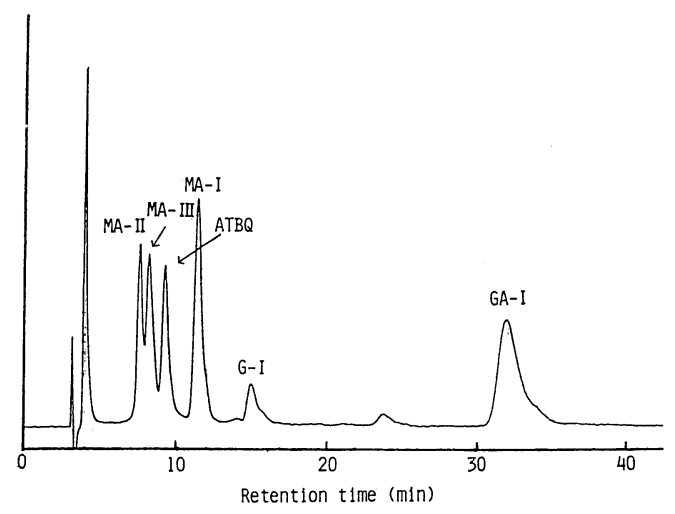

FIG. 5. HPLC of Quinoxalines from Maltose and OPD in a Weakly Acidic Medium.

The HPLC conditions are the same as for Fig. 3.

MA-III has one glucose residue at the C-2' position of the side chain of G-1.

From these results and the original structure of maltose, the structure of MA-III was assumed to be $\left(2^{\prime} S, 3^{\prime} R\right)-2$-( $2^{\prime}$-glucopyranosyloxy-3', $4^{\prime}$-dihydroxybutyl)quinoxaline.

For quantitative determination of quinoxalines formed from maltose, $5 \mathrm{~mm}$ maltose and $50 \mathrm{~mm}$ OPD were heated at $80^{\circ} \mathrm{C}$ for $3 \mathrm{hr}$ in a solvent mixture of $\mathrm{AcOH}-\mathrm{H}_{2} \mathrm{O}-\mathrm{MeOH}$ $(1: 2: 8, \mathrm{v} / \mathrm{v})$. A sample $(5 \mu \mathrm{l})$ of the reaction mixture was analyzed by HPLC, as shown in Fig. 5. The proportions of the quinoxaline derivatives were estimated to be: ATBQ, $8.9 \%$; G- $1,3.2 \%$; and GA-I, $17.1 \%$, for lowmolecular-weight derivatives; and MA-I, $14.5 \%$; MA-II, $10.2 \%$; and MA-III, $12.4 \%$, for high-molecular-weight derivatives, assuming that these quinoxaline derivatives have similar molecular extinction coefficients. As to the low-molecular-weight quinoxalines, ATBQ, G-1 and GA-I are considered to be derived from glucose liberated by the splitting of glucosidic linkages of maltose. The ratio of GA-I to ATBQ derived from glucose, as reported ${ }^{5,7)}$ is about $1: 1(22 \%: 18 \%)$, but the ratio of that derived from maltose was about $2: 1(17 \%: 8.9 \%)$. This suggests that the linkage of maltose splits rather easily when the 2,3-enediol of the reducing end residue of maltose moves to the 3,4-position. The 2,3enediol of glucose thus formed condenses 


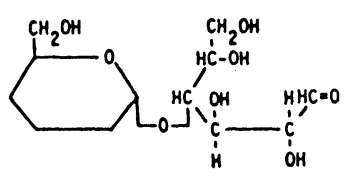

J
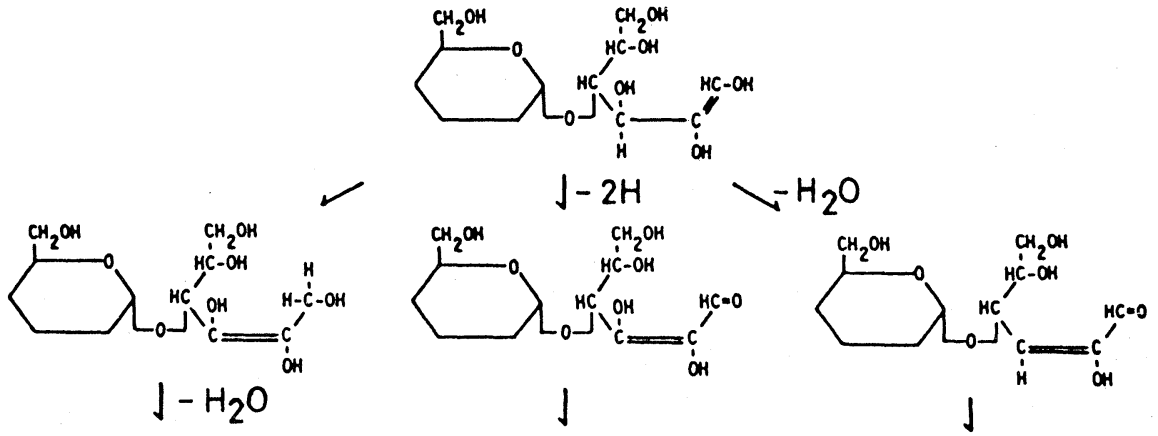

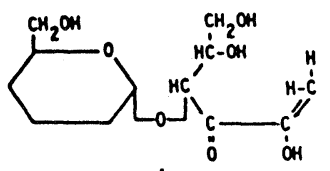

$\mathrm{J}+2 \mathrm{H}$

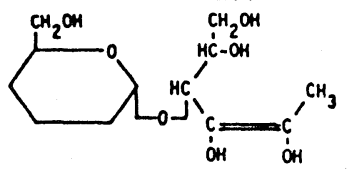

J

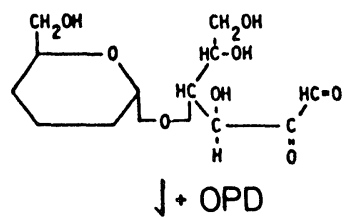

l+OPD

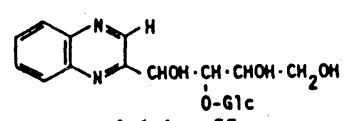

MA-II

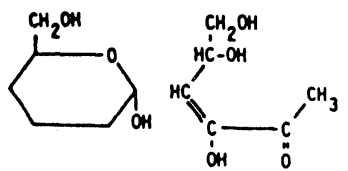

$-2 \mathrm{H}$

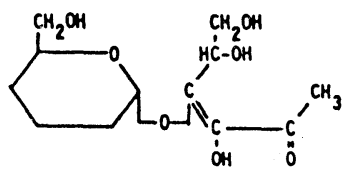

」

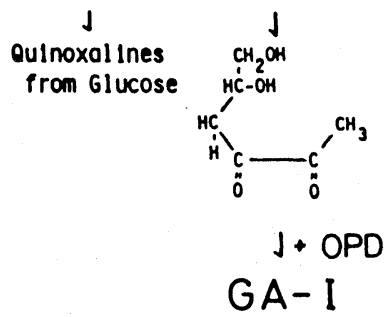

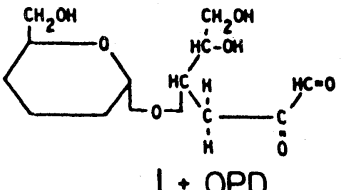

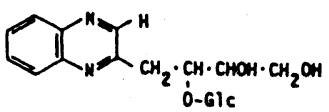

MA- III<smiles></smiles>

SCHEME II. Proposed Pathways for the Formation of Quinoxalines from Maltose and OPD in a Weakly Acidic Medium.

with OPD to form GA-1. Therefore, the amount of GA-I was higher than those of other low-molecular-weight quinoxaline derivatives. Furthermore, when 10 times as high concentrations of both maltose and OPD were used for the reaction, GA-I was predominant. This also suggests that 1,2-enediol of the reducing end residue of maltose moves to the 2,3- and 3,4-positions.

On the basis of these results, the formation 
of quinoxalines from maltose was assumed to occur as shown in Scheme II. As indicated by the scheme, it is obvious that the pathways for MA-II and -III formation are independent from that for MA-I and other low-molecularweight quinoxalines.

\section{4) Quinoxalines derived from laminaribiose}

Figure 6 shows the results of GLC analysis of quinoxalines obtained from $5 \mathrm{~mm}$ or $50 \mathrm{~mm}$ laminaribiose and à 10-fold molar excess of $\mathrm{OPD}$ at $80^{\circ} \mathrm{C}$ for $3 \mathrm{hr}$ under deoxygenated conditions. Considerable amounts of LA-I were observed when $5 \mathrm{~mm}$ laminaribiose was used for the reaction, and LA-I was supposed to have one glucose residue in its structure from its retention time. When we used a 10 times higher concentration of the substrate, only low-molecular-weight derivatives of quinoxalines were obtained. This may be due to the breakdown of glucosidic linkages of high-molecular-weight quinoxaline derivatives, because, at high concentrations of the substrate, the amount of G-1 was predominant for all quinoxalines formed. When a sample of the reaction mixture including $5 \mathrm{~mm}$ laminaribiose as a substrate was analyzed by HPLC, two peaks, LA-I and -II, were obtained. However, both materials had similar elution times, suggesting that they are stereoisomers or are greatly similar in structure. The retention times of low-molecular-weight quinoxalines on GLC and mass fragment ions on GC-MS were consistent with those of authentic GA-I, GA-II, G-1, ATBQ and GA-III, whose chemical structures are given under Materials AND Methods.

To characterize LA-I and -II, equimolar amounts $(0.5 \mathrm{M})$ of laminaribiose and OPD were heated at $80^{\circ} \mathrm{C}$ for $3 \mathrm{hr}$. The reaction mixture was applied on Sephadex G-15 with deionized water as an eluent. Each fraction was checked by TLC, and the desired fractions, LA-I and -II, were pooled and evaporated to dryness in vacuo. The residue was analyzed by GC-MS after trimethylsilylation. As shown in Fig. 7, both LA-I and -II have the same molecular ion peak at $m / z$ 916, and

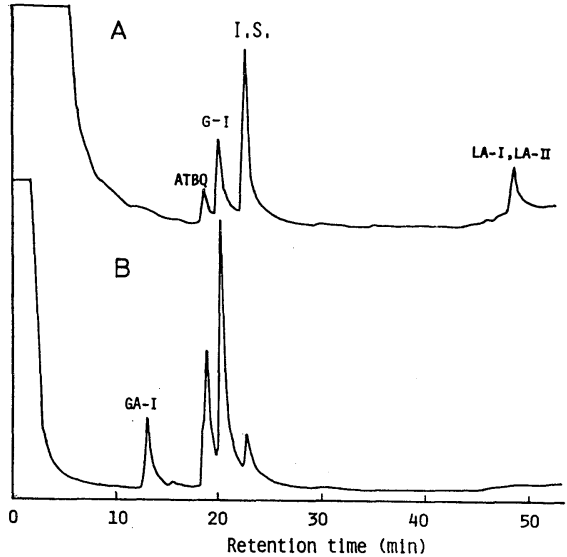

FIG. 6. GLC of TMS-Derivatives of Quinoxalines from $5 \mathrm{~mm}$ (A) or $50 \mathrm{~mm}$ (B) Laminaribiose and OPD in a Weakly Acidic Medium.

The experimental details are the same as for Fig. 1.

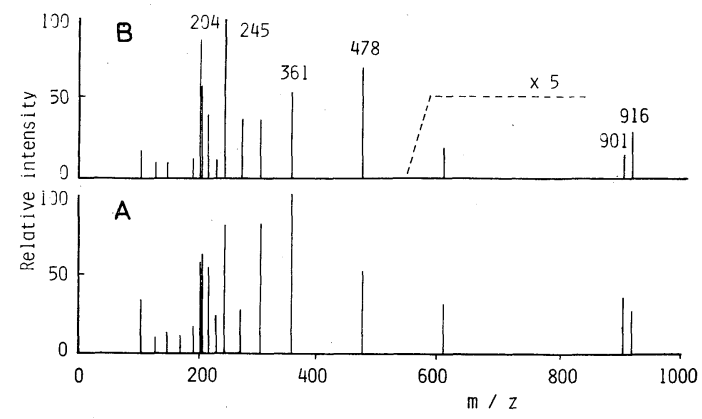

FIG. 7. Mass Spectra of TMS-Derivatives of LA-I (A) and LA-II (B).

The GC-MS conditions are the same as for Fig. 2.

characteristic fragment ion peaks at $\mathrm{m} / \mathrm{z} 204$, $205,217,245,274,307,346,478$ and 901, differing only in their relative intensities.

From the results of GC-MS, and on consideration of the original linkage of laminaribiose, LA-I and -II are assumed to be configurational isomers, at the $\mathrm{C}-1^{\prime}$ position, of 2 (1'-glucopyranosyloxy-2',3',4'-trihydroxybutyl) quinoxaline, arising through 1,2-enediol formation from the reducing end residue of laminaribiose, followed by a transition toward 2,3-enediol and 2,3-diketone formation, and then formation of a quinoxaline at the C-3 position with some isomerization, but without splitting of glucosidic linkages.

Two kinds of quinoxaline derivatives, LA-I 


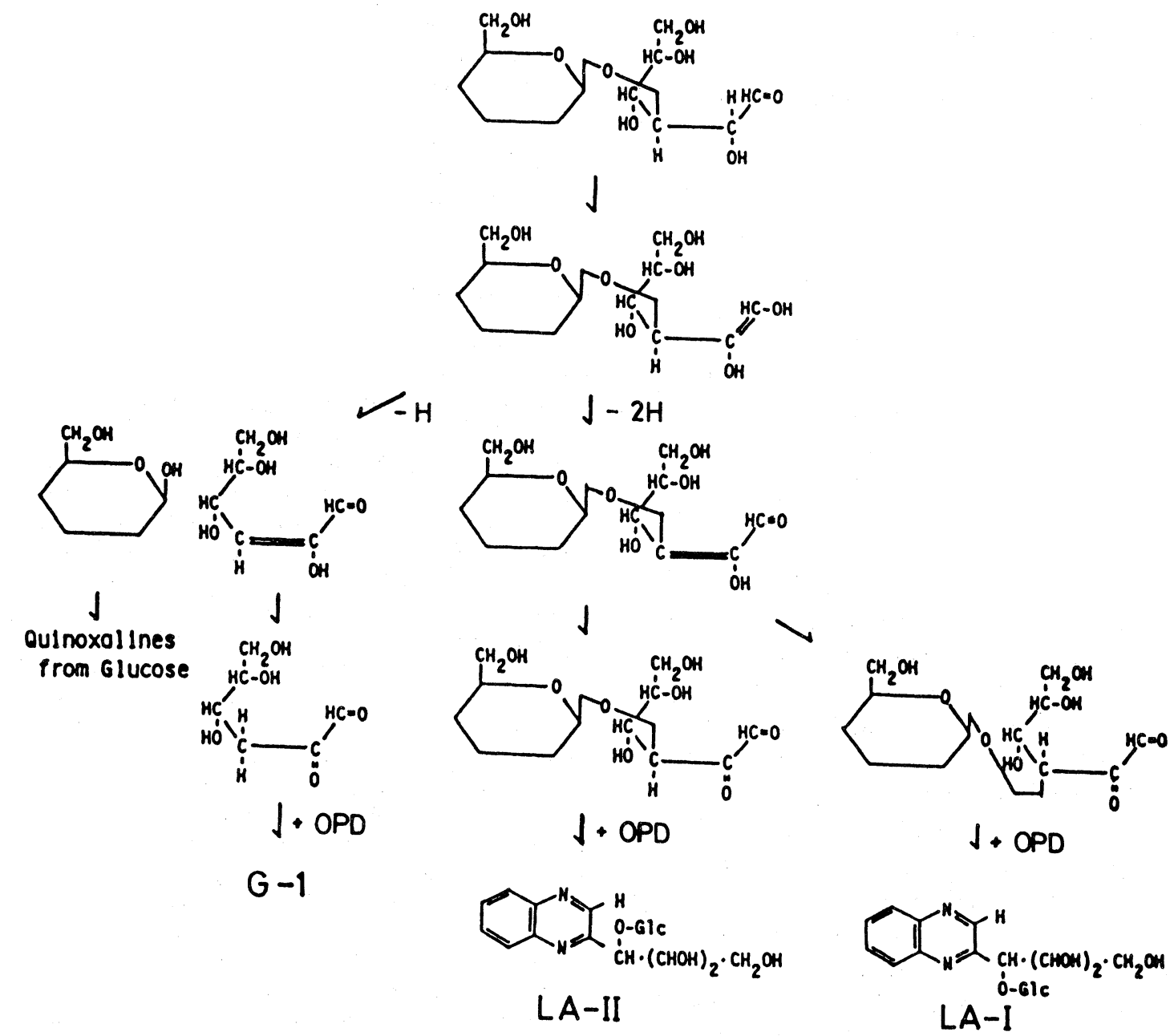

SCHEME III. Proposed Pathways for the Formation of Quinoxalines from Laminaribiose and OPD in a Weakly Acidic Medium.

and -II, were obtained in approximate proportions of $6.8 \%$ and $10.7 \%$. LA-II possibly has the original configuration of laminaribiose because of its predominant yield. The proportions of low-molecular-weight quinoxalines were found to be: ATBQ, $13.8 \%$; GA-III, $3.0 \%$; G- $1,17.0 \%$; and GA-I, $13.8 \%$, from the responses on HPLC. The ratio of G-1 to GA-I was about $10: 1$. The ratio was somewhat lower than that obtained in the case of glucose (GA-I : G-1 =4:1). This suggests that the 1,2enediol of laminaribiose splits when the enediol moves to the 2,3-position. After the condensation of the 1,2-enediol of the glucose residue thus formed with OPD, G-1 is formed rather predominantly. On splitting of the glucose residues liberated, various kinds of small quinoxaline derivatives were formed, as previously reported. ${ }^{5,7)}$ It is noteworthy that the ratio of GA-I to G-1 from laminaribiose was about $1: 1$.

The contents of LA-I and -II showed that about $20 \%$ of the glucosidic linkages remained unsplit under these reaction conditions. Two independent pathways should be considered for the formation of LA-I and -II, including isomerization of the hydroxyl residue at the C3 position of laminaribiose. On the basis of these results, the formation of quinoxaline derivatives from laminaribiose is assumed to 
occur as presented in Scheme III.

\section{5) Reaction of trehalose and sucrose with $O P D$}

Five millimolar trehalose and $50 \mathrm{~mm}$ OPD were heated in a deoxygenated and weakly acidic medium for $3 \mathrm{hr}$. Samples of the reaction mixture were analyzed by HPLC and polarography. However, no quinoxaline derivatives were observed, indicating that the glucosidic linkage of trehalose was not degraded, since trehalose has no reducing end.

On the other hand, under similar conditions, sucrose was found on polarography to be degraded to the extent of about $10 \%$, and the formation of low-molecular-weight quinoxaline derivatives was observed. The proportions of each quinoxaline derivative formed were estimated to be ATBQ, $2.5 \%$ and GA-I, $1.9 \%$, by HPLC. This indicates that after partial hydrolysis of the glucosidic linkage of sucrose, only low-molecular-weight quinoxaline derivatives were formed from the glucose and fructose liberated.

Considering the content of high-molecularweight quinoxaline derivatives obtained by the OPD method, the 1,6-linkage of disaccharides is the most resistant to degradation, ${ }^{13)}$ followed by 1,4- and 1,3-linkages, in that order. Therefore, it is suggested that this OPD degradation is similar to partial acid hydrolysis rather than to partial acetolysis as to the hydrolysis of the linkages of various disaccharides. However, it differs greatly in that non-reducing disaccharides are hydrolyzed little with the OPD treatment. This finding will be valuable for the structural examination of oligosaccharides, combined with conventional methylation and periodate oxidation methods for structural analysis.

\section{MATERIALS AND METHODS}

Materials. Maltose and sucrose were purchased from Wako Pure Chemicals, Co., Ltd.; o-phenylenediamine, from Merck, AG.; and $\beta$-phenyl-D-glucoside and trehalose, from the Sigma Chemical Co. Other reagents were of analytical grade, unless otherwise stated. Curdlan was kindly donated from Takeda Pharmaceutical Co., Ltd. and used for the preparation of laminaribiose by partial acetolysis. ${ }^{14)}$ Isomaltose was prepared by acid hydrolysis of dextran, as reported. ${ }^{15)}$

Quinoxalines G-1 [ $\left(2^{\prime} S, 3^{\prime} R\right)-2-\left(2^{\prime}, 3^{\prime}, 4^{\prime}-\right.$ trihydrobutyl)quinoxaline], GA-I [(2'S)-2-methyl-3-(2',3'-dihydroxypropyl)quinoxaline], GA-II [(3'S)-2- $\left(3^{\prime}, 4^{\prime}-\right.$ dihydroxybutyl)quinoxaline], GA-III $\left[\left(1^{\prime} R, 2^{\prime} R, 3^{\prime} R\right)-2-\left(1^{\prime}, 2^{\prime}, 3^{\prime}, 4^{\prime}-\right.\right.$ tetrahydroxybutyl)quinoxaline], and ATBQ $\{2$-(Darabino-tetrahydroxybutyl)quinoxaline $\left[\left(1^{\prime} R, 2^{\prime} S, 3^{\prime} R\right)-2\right.$ $\left(1^{\prime}, 2^{\prime}, 3^{\prime}, 4^{\prime}\right.$ - tetrahydroxybutyl)quinoxaline) $\}$ were the same specimens as used before. ${ }^{5,7)}$

Analytical methods. All evaporations were done with a rotary evaporator below $45^{\circ} \mathrm{C}$.

UV spectra were measured with a Hitachi 200-10 Spectrophotometer. GLC was performed with a Yanagimoto GCG-550F on a glass column $(0.2 \times 200 \mathrm{~cm})$ packed with $2 \%$ OV-210 on Gaschrom Q. The temperature was programmed from $140^{\circ} \mathrm{C}$ to $250^{\circ} \mathrm{C}$ at a rate of $2^{\circ} \mathrm{C}$ or $4^{\circ} \mathrm{C} / \mathrm{min}$. The sample for GLC was converted into its trimethylsilyl-ether as follows: one $\mathrm{ml}$ of the reaction mixture was evaporated to dryness. To the residue was added $0.1 \mathrm{ml}$ of pyridine containing $0.4 \mu \mathrm{mol}$ of $\beta$-phenyl D-glucoside. After the addition of $50 \mu \mathrm{l}$ of hexamethyldisilazan and $30 \mu \mathrm{l}$ of trimethylchlorosilane to the solution, the mixture was shaken vigorously with a vortex mixer. An aliquot of the supernatant was used for GLC.

HPLC was performed with an Irica High-Performance Liquid Chromatograph P-500 as the pump system and a S553 as the spectrophotometer on a column $(4 \times 250 \mathrm{~mm})$ of Irica RP-18 with a solvent system of $\mathrm{MeOH}-\mathrm{H}_{2} \mathrm{O}-$ $\mathrm{CH}_{3} \mathrm{CN}(8: 31: 1, \mathrm{v} / \mathrm{v})$ at a flow rate of $0.6 \mathrm{ml} / \mathrm{min}$, with monitoring at $320 \mathrm{~nm}$. One milliliter of the reaction mixture $(5 \mathrm{~mm})$ was diluted with deionized water, and then $10 \mu \mathrm{l}$ of the solution was analyzed.

GC-MS was performed with a Hitachi RMU-6MG Gas Chromatograph and Mass Spectrometer. The GC column contained $2 \%$ OV-1 or $2 \%$ OV-210 on Gaschrom Q and the temperature was programmed from $160^{\circ} \mathrm{C}$ to $220^{\circ} \mathrm{C}$ $\left(3^{\circ} \mathrm{C} / \mathrm{min}\right)$. The ionizing current and ionization energy were $60 \mu \mathrm{A}$ and $20 \mathrm{eV}$, respectively. The sample for GCMS was trimethylsilylated by the same method as used for GLC.

Polarography was performed with a Yanagimoto P1000 Voltammetric Analyzer. ${ }^{16)}$ The dropping mercury electrode had the following characteristics: a flow rate of mercury of $(m)=2.01 \mathrm{mg} / \mathrm{sec}$ and a drop time of $(t)=5.66$ $\mathrm{sec}$, at open circuit in distilled water with $60 \mathrm{~cm}$ mercury level. The substrate in the reaction mixture was diluted to $0.5 \mathrm{~mm}$ with $0.2 \mathrm{M}$ carbonate buffer $(\mathrm{pH} 10)$, followed by deoxygenation by nitrogen bubbling, and then analyzed by taking the polarographic limiting current due to quinoxalines at $-1.0 \mathrm{~V} v s$. saturated calomel electrode.

TLC was performed with a Merck pre-coated silica gel 60 plate with a solvent system of $n$-hexane-ether-ethanol $(2: 2: 1, \mathrm{v} / \mathrm{v})$. The colored spots were detected by heating the plate at $100^{\circ} \mathrm{C}$ for $20 \mathrm{~min}$ after spraying with a $20 \%$ $\mathrm{H}_{2} \mathrm{SO}_{4}$ aqueous solution. 
Enzymatic hydrolysis of glucosidic linkages of highmolecular-weight quinoxalines was done with glucoamylase from Rhizopus delemer. ${ }^{3,17)}$ Five $\mathrm{mg}$ of these quinoxaline derivatives was dissolved in $5 \mathrm{ml}$ of $0.1 \mathrm{M}$ acetate buffer ( $\mathrm{pH} 4.5$ ). After addition of $1 \mathrm{ml}$ of the enzyme solution (10 units, in the same phosphate buffer) to the substrate solution, the mixture was left for a week at $30^{\circ} \mathrm{C}$. A 1-ml sample of the reaction mixture was withdrawn and extracted with $n$-butanol $(1 \mathrm{ml})$, and the butanol layer was evaporated to dryness and then converted to TMS derivatives as mentioned above. The rest of the reaction mixture was heated to denature the enzyme, concentrated to a small volume, and then applied on a column $(2 \times 120 \mathrm{~cm})$ of Sephadex G-15 gel that was eluted with deionized water. To detect low-molecular-weight quinoxalines, each fraction was checked by TLC and the UV absorption spectrum was measured at $320 \mathrm{~nm}$.

Reaction of disaccharides with $O P D$. The reactions of disaccharides and OPD were essentially the same as reported before. ${ }^{5,6)}$ Disaccharides and OPD were dissolved in a mixture of $\mathrm{MeOH}-\mathrm{AcOH}-\mathrm{H}_{2} \mathrm{O}(8: 1: 2, \mathrm{v} / \mathrm{v})$ with stirring and filled up to make the final concentrations of $5 \mathrm{~mm}$ and $50 \mathrm{~mm}$, or $50 \mathrm{~mm}$ and $500 \mathrm{~mm}$, respectively, under bubbling of $\mathrm{N}_{2}$ gas, and then the mixtures were refluxed at $80^{\circ} \mathrm{C}$ under deoxygenated conditions for the given times. A portion of each solution was evaporated to dryness and analyzed by GLC. Another sample of the solution was diluted with $0.1 \mathrm{M}$ acetate buffer (pH 3.6) and analyzed by HPLC.

Acknowledgments. The authors are grateful to Dr. H. Hayashi and Dr. A. Hirota, Department of Agricultural Chemistry of our University, for their helpful discussions with regard to the structural determination of quinoxaline derivatives.

\section{REFERENCES}

1) M. Takagi, M. Mizutani, T. Nishio and S. Ono, Stärke, 22, 158 (1970).

2) N. Morita, K. Hayashi, M. Takagi and K. Miyano, Agric. Biol. Chem., 47, 757 (1983).

3) N. Morita, M. Mizutani, K. Hayashi, M. Kirihata, I. Ichimoto, H. Ueda and M. Takagi, Bull. Univ. Osaka Pref., Ser. B, 35, 59 (1983).

4) N. Morita and M. Takagi, Agric. Biol. Chem., 47, 2111 (1983).

5) N. Morita, K. Inoue and M. Takagi, Agric. Biol. Chem., 45, 2665 (1981).

6) N. Morita, Y. Daido, H. Hayashi and M. Takagi, Agric. Biol. Chem., 47, 765 (1983).

7) N. Morita, K. Inoue and M. Takagi, Agric. Biol. Chem., 47, 1329 (1983).

8) N. Morita, Y. Daido and M. Takagi, Agric. Biol. Chem., 48, 2753 (1984).

9) N. Morita, Y. Daido and M. Takagi, Agric. Biol. Chem., 48, 3161 (1984).

10) T. Sugiyama and T. Usui, Agric. Biol. Chem., 44, 883 (1980).

11) K. K. S. Gupta and S. N. Basu, Carbohydr. Res., 72, 139 (1979).

12) M. Takagi, M. Mizutani and K. Tsuchiya, Bull. Univ. Osaka Pref., Ser. B, 24, 43 (1972).

13) K. Fujimoto, K. Matsuda and K. Aso, Nippon Nôgeikagaku Kaishi, 36, 770 (1962).

14) W. J. Whelan, "Methods in Carbohydrate Chemistry," Vol. 1, ed. by R. L. Whistler and M. L. Wolfrom, Academic Press, New York, 1962, pp. $330 \sim 333$.

15) J. R. Turvey and W. L. Whelan, Biochem. J., 67, 49 (1957).

16) K. Hayashi and M. Takagi, Bull. Chem. Soc. Jpn., 54, 1437 (1981).

17) K. Hiromi, Z. Hamauzu, K. Takahashi and S. Ono, J. Biochem., 59, 411 (1966). 